\title{
Parental mediation, cyber victimization, adjustment difficulties, and adolescents with autism spectrum disorder
}

\author{
Michelle F. Wright \\ Pennsylvania State University, State College, PA, United States \& Masaryk University, Brno, Czech Republic
}

\begin{abstract}
Parental mediation of technology use is proposed to protect against the risk of cyber victimization and the associated negative consequences. Although the buffering effects of parental mediation of technology use are currently being investigated, little attention has focused on whether parental mediation protects against the depression, anxiety, and loneliness associated with cyber victimization among adolescents with autism spectrum disorders. The present study focused on this gap in the literature by investigating the buffering effect of parental mediation on the associations between cyber victimization and depression, anxiety, and loneliness. Participants were $1286^{\text {th }}$ through $8^{\text {th }}$ graders from the Midwestern United States (ages range from 11-16 years old; 89\% male), and they completed questionnaires on their perceptions of parental mediation of technology use, cyber victimization, face-to-face victimization, depression, loneliness, and anxiety. After controlling for face-to-face victimization, the findings revealed that high levels of perceived parental technology mediation made the relationship between cyber victimization and depression more negative, while lower levels of perceived parental technology mediation made the association more positive. These patterns were not found for anxiety or loneliness.
\end{abstract}

Keywords: cyber victimization; parental mediation; depression; anxiety; loneliness; autism

\section{Introduction}

Growing up in a digitally connected world, many adolescents consider digital technologies an important part of their lives. These technologies allow almost constant connection with the world, afford access to a variety of information, and provide adolescents with entertainment. Although there are many conveniences associated with adolescents' use of digital technologies, they are also exposed to risks, including sexual predation, violence, and pornography (Smahel, Wright, \& Cernikova, 2014). Another risk associated with adolescents' digital technology use is cyber victimization. This risk has received attention from educators, parents, researchers, and the public because some victims of cyberbullying experience an assortment of adjustment difficulties, including depression, Ioneliness, and anxiety (Bauman, Toomey, \& Walker, 2013; Campbell, Spears, Slee, Butler, \& Kift, 2012; Hinduja \& Patchin, 2008; Kowalski \& Limber, 2013; Wright, 2015).

Because it is unlikely that digital technologies will disappear anytime soon or that adolescents will discontinue use of these technologies, researchers have focused on factors which might reduce the effects of the adjustment difficulties associated with cyber victimization. Parental mediation of technology use is one factor receiving increased attention. In this literature, parental mediation buffers against the depression and anxiety resulting 
from cyber victimization (Lwin, Stanaland, \& Miyazaki, 2008; Mesch, 2009; Wright, 2015). These studies include samples of typical developing adolescents. Adolescents with autism spectrum disorders have not received much attention in the cyberbullying literature. It is important to understand adolescents with autism spectrum disorders' involvement in bullying because they are twice as likely to be victims of these behaviors (Rose \& Monda-Amaya, 2011).

Autism spectrum disorder is a new diagnosis which encompasses autistic disorder, Asperger's disorder, childhood disintegrate disorder, and pervasive developmental disorder, according to the Diagnostic and Statistical Manual of Mental Disorders (American Psychiatry Association, 2013). These separate diagnoses were not consistently applied in various U.S. clinics and treatment centers, resulting in a combined diagnosis of autism spectrum disorder. Adolescents with autism spectrum disorder often have trouble with social skills, making them awkward in many social situations (Millea, Shea, \& Diehl, 2013). They might engage in repetitive behaviors and be hypersensitive to environmental stimuli. These characteristics make these adolescents easy targets for bullies because many bullies are skilled at noticing others who are different (Cappadocia, Weiss, \& Pepler, 2012; Heinrichs, 2003; Sterzing, Shattuck, Narendorf, Wagner, \& Cooper, 2012). Many bullies enjoy aggravating their victims, which might make adolescents with autism spectrum disorder easy targets due to their hypersensitivity to the environment (Heinrich, 2013).

It is important to understand factors that might mitigate the negative adjustment difficulties associated with adolescents with autism spectrum disorders' experience of cyber victimization. The purpose of the present study was to examine whether parental mediation of technology use would buffer against depression, anxiety, and loneliness associated with cyber victimization among adolescents with autism spectrum disorders.

\section{Cyber Victimization and Autism Spectrum Disorder}

Being targeted for purposeful, hostile, and embarrassing or intimidating behaviors via the internet and other digital technologies is referred to as cyber victimization (Ferdon \& Hertz, 2007; Grigg, 2010; Kowalski \& Limber, 2007; Wolak, Mitchell, \& Finkelhor, 2007; Ybarra, Diener-West, \& Leaf, 2007). Although the definition of cyber victimization includes some overlap with face-to-face victimization, there are a few notable differences. In particular, cyber victimization does not always involve an imbalance of power between the target and the bully and it might occur once, with profound emotional difficulties. There are a variety of different victimization behaviors that are classified as cyber victimization, including receiving abusive emails and being the target of identity theft, harassment, physical threats, social exclusion, verbal assaults, and humiliation (Wolak et al., 2007; Ybarra \& Mitchell, 2004). More severe forms of cyber victimization exist as well, such as having embarrassing or explicit pictures or videos distributed of oneself, happy slapping, flaming, trolling, and hacking (Gillespie, 2006; Rideout, Roberts, \& Foehr, 2005; Smith et al., 2008). In the present research, cyber victimization was defined as experiencing hostile and embarrassing behaviors online, such as being the target of social exclusion, verbal assaults, and humiliation.

The internet is an important modern day tool. This is because the internet removes the physical barriers and limitations present with many face-to-face interactions. These features of the internet have led clinicians and researchers to recognize the benefits of using the internet and other digital technologies to help individuals with disabilities (Domingo, 2012; Hassett, Lowder, \& Rutan, 1992). Adolescents with autism spectrum disorder use the internet and digital technologies, although their rates of use are slightly below their peers with other types of disabilities (Mazurek, Shattuck, Wagner, \& Cooper, 2012). Kuo, Orsmond, Coster, and Cohn (2014) found that $98 \%$ of adolescents with autism spectrum disorder in their sample utilized home computers at least five hours a day. Adolescents with autism spectrum disorders often prefer using non-social media, such as television and video games, instead of social media, including email and internet chatting (Mazurek et al., 2012). Use of the internet and other digital technologies increases adolescents' risk for negative online experiences, such as cyber victimization (Didden et al., 2009; Smith et al., 2008; Ybarra \& Mitchell, 2004).

Little attention has been given to cyber victimization among adolescents with autism spectrum disorders. One study to date has focused on this topic. In this study, Kowalski and Fedina (2011) found that adolescents who were diagnosed with Asperger syndrome or ADHD experienced cyber victimization and that they appeared to have greater levels of physical and psychological health problems when compared to typically-developing 
adolescents who were uninvolved in cyberbullying. Other research has focused on cyber victimization among adolescents with intellectual or attentional disabilities. In this research, Didden and colleagues (2009) found that $2 \%$ to $18 \%$ of the 114 youths in their research reported experiencing cyberbullying. In other research, Wells and Mitchell (2014) found that adolescents with disabilities were more likely to report distressing cyber victimization in comparison to adolescents without disabilities. Adolescents with ADHD were more likely to report cyber victimization than adolescents without ADHD (Heiman, Olenik-Shemesh, \& Eden, 2015). Overall, these studies conclude that adolescents with special needs are at risk of experiencing cyber victimization. Furthermore, when they experience cyber victimization, they also report adjustment difficulties, such as depression, anxiety, and loneliness. These adjustment difficulties are similar to their victimized peers without disabilities (Hu, Chou, \& Yen, 2016; Van Roekel, Scholte, \& Didden, 2010). Consequently, it is important to understand factors that mitigate the harm associated with cyber victimization.

\section{Parental Mediation of Technology Use}

Parental mediation of technology is defined as parents' use of a variety of prevention strategies that are implemented to manage their children's relationship with electronic media (Livingstone \& Helsper, 2008). Parents' beliefs about their competency to mediate their children's online activities is also important for determining the mediational strategies that parents implement (Nikken \& de Haan, 2015). These strategies might include setting rules regarding their children's consumption of electronic media. Parents might discuss appropriate use with their children and set limits on what is allowed to be viewed (Dehue, Bolman, Vollink, \& Pouwelse, 2012). Furthermore, parents might set time limits on their children's technology use. Effective parental mediation involves parents maintaining an open dialogue with their children regarding appropriate content to view and how to use online tools. Parents who believed that digital media have positive effects were more likely to use active mediation strategies, while those parents with negative attitudes regarding digital media use were more likely to use restrictive mediation strategies (Nikken \& Schols, 2015). Sometimes parents will set rules concerning their children's involvement in negative online behaviors, such as cyberbullying.

The literature on parental mediation of technology use has focused on how these mediational strategies reduce adolescents' exposure to online risks. In particular, parents who utilized monitoring software and created technology rules with their children had children who spent less time online and disclosed less personal information online (Navarro, Yubero, \& Larranaga, 2015). Spending less time online and disclosing less personal information online reduced adolescents' risk of cyber victimization. In this literature, Mesch (2009) found that parents' use of monitoring strategies, such as checking on what websites their children accessed, reduced their children's risk of experiencing cyber victimization when compared to children who did not report that their parents employed such strategies. . Other research on parental mediation of technology use focuses on how such strategies buffer against the negative consequences associated with these behaviors. Higher levels of parental mediation lessened the relationship between cyber victimization and depression and anxiety (Wright, 2015). On the other hand, lower levels of parental mediation increased adolescents' risk of depression and anxiety after experiencing cyber victimization. Thus far, no research has focused on whether parental mediation of technology use reduces adolescents with autism spectrum disorders' risk of cyber victimization. One study examined differences in parental mediational strategies among ADHD and non-ADHD adolescents (ArrizabalagaCrespo, Aierbe-Barandiaran, \& Medrano-Samaniego, 2010). Their findings revealed that adolescents with ADHD experienced more restrictive and instructive parental mediation than non-ADHD adolescents. Although not focused on adolescents with ADHD, Wright (in press) found that instructive mediation protects against the depression and anxiety resulting from cyber victimization. It might be likely that parental mediation of technology use protects adolescents with autism spectrum disorders from the negative consequences associated with experiencing cyberbullying. In particular, parents might use restrictive mediation strategies with their autistic children as a means to protect their children from online risks and harm. Due to increasing cognitive abilities, adolescence is often a time when children begin to question parents' rules. Noncompliant behaviors increase during adolescence and autistic adolescents are no exception to engaging in such behaviors. Consequently, they might feel highly annoyed and increasingly noncompliant because of their parents' overprotectiveness regarding technology. However, Wright found the restrictive strategies exacerbated the relationship between cyber victimization and depression and anxiety. 


\section{The Present Study}

The aim of the present study was to investigate the buffering effect of parental mediation of technology use in the association between cyber victimization and depression, anxiety, and loneliness among adolescents with autism spectrum disorders. Face-to-face victimization was controlled for in the analyses because of the high correlation between cyberbullying and face-to-face victimization (Smith et al., 2008; Wright \& Li, 2012). Gender was also included as a control variable, due to inconsistent findings in gender differences for cyber victimization.

The following research questions were used to guide this study:

(1) What is the relationship among cyber victimization, parental mediation of technology use, depression, anxiety, and loneliness, while controlling for gender and face-to-face victimization?

(2) What, if any, buffering effect does parental mediation of technology use have on the association between cyber victimization and depression, anxiety, and loneliness, while controlling for gender and face-to-face victimization?

\section{Method}

\section{Participants}

Participants were 128 adolescents (89\% male; ages range from 11-16 years old) with autism spectrum disorders in the $6^{\text {th }}, 7^{\text {th }}$, or $8^{\text {th }}$ grade at sixteen middle schools, located in the suburbs of a large Midwestern city in the United States. Adolescents had one of the following autism spectrum disorders: autistic disorder, Asperger syndrome, or pervasive development disorder. The sixteen middle schools were located in predominantly middle-class neighborhoods, with about $32 \%$ of students receiving free or reduced lunch. The participants selfidentified as white (86\%), Black/African American (3\%), Latino/a (1\%), and Asian (10\%). Income data was not collected from adolescents' families.

\section{Procedures and Measures}

The research was approved by the principal investigator's university. Of the sixteen middle schools, twelve required district approval to collect data. The other schools required principal-level approval. APA ethical standards were followed throughout the conduction of this study.

Thirty middle schools were selected from a list of over one hundred and fifty public schools. School principals were sent an email, describing the study's purpose, which students are invited to participate, what these students would be expected to do, and how long the study would take. From this list of thirty middle schools, sixteen school principals expressed interest in the study and setup meetings with the principal investigator. The principal investigator met with school principals and teachers to describe the research project, who would participate, and how long the study would take. Afterward, the principal investigator met with school psychologists to identify adolescents with the diagnosis of an autism spectrum disorder, either autistic disorder, Asperger syndrome, or pervasive developmental disorder, and who were able to read the questionnaires without the help from a paraprofessional. Data on what specific autism disorder diagnosis that the adolescents had was not collected. There were 201 eligible adolescents identified. Special announcements were made to the adolescents, with a graduate assistance who had specialized training in autism spectrum disorders present. The announcement described the study's purposes, what they would be expected to do, and how long the study would take. A letter and parental permission slip were passed out to adolescents. There were 201 parental permission slips sent home. Of these, 138 were returned with permission, 45 were returned without permission, and the rest were never returned. Data was collected in the fall of 2015. Before completing the questionnaires, adolescents provided their assent. Five did not provide their assent, and consequently they were sent to a different classroom to work on another activity. Another five adolescents were not present during data collection. Adolescents completed questionnaires on demographic information, including gender, age, and ethnicity, their face-to-face victimization and cyber victimization, parental mediation, depression, anxiety, and loneliness. Trained research assistants administered the questionnaires and answered any questions that the 
adolescents might have had. All research assistants had some training in special education, and were led by a graduate student with experience in this area.

Face-to-face victimization. Adolescents answered how often they experienced face-to-face victimization. Twelve items were included on this questionnaire and these items were rated on a scale of 1 (not at all) to 5 (all of the time) (Wright, Li, \& Shi, 2014). Directions at the beginning of the study asked adolescents to answer the questions according to what has happened to them within the current school year. Sample items included: "A peer called me insulting names" and "A peer spread rumors about me to get others not to like me". Cronbach's alpha was .83 for face-to-face victimization.

Cyber victimization. Similar to the face-to-face victimization questionnaire, this questionnaire assessed how often adolescents experienced victimization online or via text messages (Wright \& Li, 2013). The questionnaire included eight items, which were rated on a scale of 1 (not at all) to 5 (all of the time). Directions at the beginning of the questionnaire asked adolescents to answer the questions according to their experiences within the current school year.

Items included: "A gossiped about me to others online or through text messages to make the others not like me," "A peer ignored me online or through text message, even though I really wanted to talk to him/her," "A peer teased me in a mean way online or through text messages," "A peer tried to turn others against me online or through text messages because he/she was mad at me," "A peer told me that he/she would not be friends with me online or through text messages if I did not do what he/she said," "A peer insulted me by calling me mean and humiliating names online or through text messages," "A peer spread rumors about me online or through text messages" and "A peer posted or sent nasty and humiliating messages to me". Cronbach's alpha was .86.

Parental mediation of technology use. This questionnaire assessed adolescents' perceptions of whether their parents were involved in their digital media use (Arrizabalaga-Crespo et al., 2010). Items were rated on a scale of 1 (completely disagree) to 5 (completely agree). This questionnaire included eight questions. Sample items included: "My parents explain to me issues related to certain websites" and "My parents tell me what websites I should visit or which I shouldn't visit". Cronbach's alpha was .91.

Depression. The Center for Epidemiological Studies Depression Scale was used to assess adolescents' depressive symptoms (Radloff, 1977). The directions of the questionnaire asked adolescents to rate twenty items on a scale of 0 (rarely or none of the time) to 3 (most or all of the time). Sample items included: "I was bothered by things that usually don't bother me" and "I did not feel like eating, my appetite was poor". Cronbach's alpha was .86 .

Anxiety. The Multidimensional Anxiety Scale for Children was used to assess adolescents' anxiety symptoms (March, Parker, Sullivan, Stallings, \& Conners, 1997). There were thirty-nine items, which were rated on a scale of 0 (never true about me) to 3 (often true about me). A sample item included: "I get scared when my parents go away". Cronbach's alpha was 87 for anxiety.

Loneliness. The Revised UCLA Loneliness Scale was used to assess adolescents' symptoms of loneliness (Russell, 1996). There were twenty items, which were rated on a scale of 1 (never) to 4 (often). A sample item included: "I feel isolated from others". Cronbach's alpha was .90 for loneliness.

\section{Analytic Plan}

Three multiple hierarchical regression analyses were conducted for each of the adjustment outcomes (i.e., depression, loneliness, anxiety). Predictor variables included cyber victimization and parental mediation of technology use. Gender and face-to-face victimization were included as covariates. In Block 1, gender and faceto-face victimization were included. In Block 2, cyber victimization was included. In Block 3, parental mediation of technology use was included. In Block 4, an interaction was included between cyber victimization and parental mediation of technology use. All continuous predictor variables were centered. To probe interactions, the Interaction! program was used (Soper, 2013). This program provides the simple slopes of the regression lines, the unstandardized betas, and significance levels. 


\section{Results}

Before hypotheses were tested, correlations were performed among all variables (see Table 1). Cyber victimization was related positively to face-to-face victimization, depression, anxiety, and loneliness, while it was associated negatively with parental mediation of technology use. Parental mediation of technology use was related positively to depression, anxiety, and loneliness. Depression was associated positively with anxiety and loneliness. Similarly, anxiety was related positively to loneliness. Face-to-face victimization was related positively to depression, anxiety, and loneliness, whereas this variable was associated negatively with parental mediation of technology use.

Table 1. Correlations among Face-To-Face Victimization, Cyber Victimization, Parental Mediation, Depression, Anxiety, and Loneliness.

\begin{tabular}{lllllll}
\hline & 1 & 2 & 3 & 4 & 5 & 6 \\
\hline 1. Face-to-face Victimization & -- & & & & & \\
2. Cyber Victimization & $.51^{* * *}$ & -- & & & & \\
3. Parental Mediation of Technology Use & $-.28^{* *}$ & $-.30^{* * *}$ & --- & & & \\
4. Depression & $.38^{* * *}$ & $.30^{* *}$ & $-.28^{* *}$ & --- & & \\
5. Anxiety & $.31^{* * *}$ & $.26^{* *}$ & $-.20^{*}$ & $.41^{* *}$ & --- & \\
6. Loneliness & $.21^{*}$ & $.18^{*}$ & $-.18^{*}$ & $.27^{* *}$ & $.19^{*}$ & --- \\
$M(S D)$ & $3.26(1.06)$ & $2.97(.97)$ & $2.63(.74)$ & $1.98(.68)$ & $1.81(.79)$ & $2.16(1.00)$ \\
\hline
\end{tabular}

Notes: ${ }^{*} p<.05 .{ }^{* \star} p<.01 .{ }^{* \star \star} p<.001$.

Table 2. Cyber Victimization, Parental Mediation of Technology Use, Depression, Anxiety, and Loneliness.

\begin{tabular}{|c|c|c|c|c|c|c|c|c|c|}
\hline & \multicolumn{3}{|c|}{ Depression } & \multicolumn{3}{|l|}{ Anxiety } & \multicolumn{3}{|c|}{ Loneliness } \\
\hline & $\beta$ & $R^{2}$ & $\Delta R^{2}$ & $\beta$ & $R^{2}$ & $\Delta R^{2}$ & $\beta$ & $R^{2}$ & $\Delta R^{2}$ \\
\hline Block 1 & & .36 & $.36 *$ & & .38 & $.38 *$ & & .30 & $.30 *$ \\
\hline Gender & .02 & & & .03 & & & .02 & & \\
\hline F2F Vic & $.21 *$ & & & $.23^{*}$ & & & $.18 *$ & & \\
\hline Block 2 & & .43 & $.07 * \star \star$ & & .44 & $.06 * \star \star$ & & .35 & $.05^{\star \star *}$ \\
\hline Gender & .01 & & & .01 & & & .01 & & \\
\hline F2F Vic & $.17 *$ & & & $.21 *$ & & & $.17^{*}$ & & \\
\hline CVic & $.30 * \star *$ & & & $.30 * * \star$ & & & $.33^{* \star *}$ & & \\
\hline Block 3 & & .47 & $.04^{* \star \star}$ & & .46 & $.02 * *$ & & .38 & $.03 * *$ \\
\hline Gender & .01 & & & .01 & & & .01 & & \\
\hline F2F Vic & $.19 *$ & & & $.20 *$ & & & $.18^{*}$ & & \\
\hline CVic & $.28 * \star$ & & & $.29 * *$ & & & $.26 * \star$ & & \\
\hline PM & $-.21 *$ & & & $-.23^{*}$ & & & $-.22 *$ & & \\
\hline Block 4 & & .49 & $.02 * \star$ & & .47 & .01 & & 39 & .01 \\
\hline Gender & .01 & & & .01 & & & .02 & & \\
\hline F2F Vic & .15 & & & .21 & & & .19 & & \\
\hline CVic & $.23 *$ & & & .28 & & & .25 & & \\
\hline PM & $-.18 *$ & & & -.19 & & & -.17 & & \\
\hline CVic $\times$ PM & $-.27 * \star$ & & & -.11 & & & -.09 & & \\
\hline
\end{tabular}

Notes: F2F Vic = Face-to-face Victimization; CVic = Cyber Victimization; PM = Parental Mediation of Technology Use. ${ }^{*} p<.05$. $* \star p<.01 . * * \star p<.001$.

For the multiple regression analyses, gender was not related to depression, anxiety, or loneliness (see Table 2). Face-to-face victimization and cyber victimization were related positively to depression, anxiety, and loneliness. Parental mediation of technology use was associated negatively with all three adjustment variables. A two-way interaction was included between cyber victimization and parental mediation of technology use for the three regression models. The findings revealed that high levels of perceived parental mediation of technology use $(B=$ $.17, S E=.08, p<.001+1 \mathrm{SD}$ ) made the relationship between cyber victimization and depression more negative, 
while lower levels of perceived parental mediation of technology use made the association more positive ( $B=$ $.21, S E=.11, p<.001-1 \mathrm{SD})$. The interactions for anxiety and loneliness were not significant.

\section{Discussion}

The purpose of this study was to examine the moderating role of parental mediation of technology use in the association between cyber victimization and depression, anxiety, and loneliness among adolescents with autism spectrum disorders. Aligned with previous research, cyber victimization was associated positively with depression, anxiety, and loneliness, while it was related negatively to parental mediation of technology use (Campbell et al., 2012; Kowalski \& Limber, 2013; Mesch, 2009; Navarro et al., 2015; Wright, 2015). The results of the present study have the potential to contribute to the burgeoning literature focused on how parental mediation of technology use protects against the negative adjustment consequences associated with cyber victimization. In addition, these findings highlight the need for further research focusing on the online experiences of adolescents with autism spectrum disorders.

Parental mediation of technology use might function as a form of social support. It allows adolescents, potentially even those with autism spectrum disorder, to discuss their exposure to problematic online situations, like cyberbullying, with their parents (Livingstone, Haddon, Görzig, \& Ólafsson, 2011). Such discussion might allow parents the opportunity to discuss strategies to prevent or reduce adolescents' experience of online risks (Wright, 2015). Experiencing a negative online situation, even one that is somewhat minor, might lead adolescents to seek out support and guidance from their parents regarding what they experienced. When it comes to technical problems or extremely problematic online experiences, adolescents might especially seek out the support of their parents (Nikken \& de Haan, 2015; Talves \& Kalmus, 2015). Parents should recognize the supportive role that they have in adolescents' digital media use, and how they can help to offset cyberbullying victimization and negative adjustment difficulties. Thus, parents need to be involved in their children's digital media use to help protect their children from the depression, anxiety, and loneliness that might result as a consequence of cyberbullying victimization. Because parental mediation of technology use is likely to result in continuing dialogue about online risks and opportunities, parents might continue to offer solutions and support for cyber victimization, even when their children do not need advice (Livingstone et al., 2011; Wright, 2015). Having someone in their life whom they know will be there for them reduces adolescents' risk of cyber victimization (Mesch, 2009; Wright, 2016).

The moderating effect of parental mediation of technology use on the relationships between cyber victimization and depression, anxiety, and loneliness among adolescents with autism spectrum disorders provides a better understanding of the study's results. Higher levels of parental mediation of technology use reduced the association between cyber victimization and depression. Opposite patterns were found for lower levels of parental mediation of technology use. Such findings are consistent with the literature indicating that parental mediation of technology use reduces adolescents' risk of cyberbullying (Mesch, 2009; Navarro et al., 2015). Furthermore, the results regarding the buffering effect of parental mediation of technology use is also consistent with the literature (Wright, 2015). Social support helps to buffer against the negative consequences associated with a variety of negative online and offline experiences among adolescents (Cheng, K. Cheung, \& C. Cheung, 2008; Ybarra, Mitchell, Palmer, \& Reisner, 2015). As a form of social support, parental mediation of technology use might involve parents sharing effective strategies for dealing with and avoiding online risks. In addition, parenting mediation of technology should involve an ongoing conversation about online risks and opportunities. This continuous conversation makes it possible for adolescents to express their concerns and ask for tips for avoiding negative online experiences. It is not likely that negative online experiences can always be avoided, and when adolescents encounter such experiences, they feel secure because they know that they have their parents support. Such knowledge mitigates the adjustment difficulties related to experiencing online risks, including cyber victimization.

Cyber victimization is associated with anxiety and loneliness (Brighi, Guarini, Melotti, Galli, \& Genta, 2012; Jackson \& Cohen, 2012). Although the present study found support for these associations, it did not find that parental mediation of technology use moderated the associations between cyber victimization and anxiety and loneliness among adolescents with autism spectrum disorders. Parental mediation of technology use has been found in other research to moderate these relationships, particularly for anxiety (Wright, 2016; Wright, in press). 
These other studies involved typically developing adolescents and not adolescents with autism spectrum disorders. Differences in these samples might account for not finding that parental mediation buffered against the anxiety associated with cyber victimization. In her research, Wright (in press) proposed that loneliness might be an adjustment difficulty that is not influenced by parental mediation because loneliness is usually related to peer rejection. Rejected adolescents often have poor peer relationships, with makes them susceptible to online and offline victimization (Asher, Parkhusrt, Hymel, \& Williams, 1990; Wright \& Li, 2013). Consequently, parental mediation of technology use might not protect some adolescents from loneliness as they might be vulnerable to peer rejection and poor peer relationships. This might be especially true of adolescents with autism spectrum disorders since they are more likely to experience peer rejection and victimization.

Follow-up research should investigate different parental mediation strategies for technology use to examine any potential differential patterns between the association between cyber victimization and adjustment difficulties. Such a future direction is important because there is research evidence that parents utilize different parental mediational strategies for ADHD versus non-ADHD adolescents (Arrizabalaga-Crespo et al., 2010). Adolescents with ADHD reported that their parents used more restrictive and instructive mediational strategies for their technology use than adolescents without ADHD. In her research, Wright (in press) found that restrictive parental mediation increased adolescents' risk of cyber victimization and the resulting anxiety and depression, while instructive parental mediation decreased this risk. Wright concluded that restrictive mediation might lead parents to enforce strict rules and policies for their children's technology use. Restrictive mediation might be a form of overprotective parenting. Overprotective parents use fear to parent their children, leading their children vulnerable to negative online experiences (Clarke, Cooper, \& Creswell, 2013; Lereya, Samara, \& Wolke, 2013). Although they enforce such rules, parents who utilize restrictive mediation might not discuss ways to mitigate online risks (Mesch, 2009). Consequently, as adolescents become more immersed in digital technologies, they are unable to avoid even minor online harm and they especially do not know how to deal with these situations (Smahel et al., 2014). Because adolescents with parents who utilize restrictive mediation are potentially less likely to learn the skills necessary to mitigate such harm, they might be more prone to cyber victimization and the negative adjustment difficulties. On the other hand, instructive mediation involves parents who openly discuss online experiences with their children. During these conversations, parents discuss cyberbullying and strategies for mitigating online risks (Mesch, 2009; Nikken \& de Haan, 2015; Talves \& Kalmus, 2015). Children whose parents utilize instructive mediation might learn to avoid problematic online experiences and if they encounter such experiences they are prepared to deal with it effectively.

\section{Recommendations}

The aim of the present study was to focus on adolescents with autism spectrum disorders' experience of cyberbullying. To date, only a handful of studies have focused on cyber victimization and the associated adjustment difficulties experienced by these adolescents. It is important to understand cyber victimization among adolescents with autism spectrum disorders because they are consumers of online content and are involved in online communications, making them vulnerable to negative online experiences. Parents need to recognize the benefits of parental mediation of technology use. Furthermore, educators might also find it helpful to develop strategies and solutions to help adolescents with autism spectrum disorders deal with cyber victimization. Such strategies and solutions could reduce these adolescents' experience of adjustment difficulties. Furthermore, parents and educators should work together to help ensure adolescents' online safety and effective coping skills. Parents and educators must develop an awareness of effective strategies for combating cyber victimization. Intervention and prevention programs are needed to reduce cyber victimization, and such programs must include adolescents with autism spectrum disorders.

\section{Limitations}

There were a few notable limitations of the present study. In particular, future research should investigate a variety of parental mediation strategies, such as co-viewing, instructive, and restrictive, to determine whether these strategies differentially reduce adolescents with autism spectrum disorders' exposure to cyberbullying and the associated adjustment difficulties. Another potential future direction is to focus on cyberbullying perpetration as well. Less attention has focused on how parental mediation strategies might reduce cyberbullying perpetration. Some adolescents with autism spectrum disorders, such as those with Asperger 
syndrome, are a bit more likely to engage in bullying perpetration. It is important to understand factors which reduce adolescents' perpetration of cyberbullying. The concurrent nature of the present study makes it difficult to understand the long-term associations between parental mediation strategies, cyber victimization, and adjustment difficulties. More research attention is needed on this topic to understand the long-term benefits of parental mediation strategies and whether certain strategies are more or less effective for reducing cyberbullying risks over time. Another focus might be the quality of the parent-child relationship and parenting styles.

\section{Conclusion}

The present research is one of the few studies focused on investigating the mitigating or buffering role of parental mediation of technology use in the relationships between cyber victimization, depression, anxiety, and loneliness among adolescents with autism spectrum disorders. This association was moderated by high and low levels of parental mediation strategies, although this was found for depression only. These findings underscore the importance of further studying protective factors for reducing the adjustment difficulties associated with cyber victimization. Parents and educators need to be made aware of the importance of discussing strategies and solutions for dealing with cyber victimization with adolescents. Prevention and intervention programs targeting cyber victimization should be developed, especially programs that include all adolescents, like those adolescents with autism spectrum disorders.

\section{References}

American Psychiatric Association. (2013). Diagnostic and statistical manual of mental disorders (5th ed.). Washington, DC: Author.

Arrizabalaga-Crespo, C., Aierbe-Barandiaran, A., \& Medrano-Samaniego, C. (2010). Internet uses and parental mediation in adolescents with ADHD. Revista Latina de Comunicacion, 65, 561-571.

Asher, S. R., Parkhurst, J. T., Hymel, S., \& Williams, G. A. (1990). Peer rejection and loneliness in childhood. In S. R. Asher \&J. D. Coie (Eds.), Peer rejection in childhood: Cambridge studies in social and emotional development (pp. 253-273). New York, NY: Cambridge University Press.

Bauman, S., Toomey, R. B., \& Walker, J. L. (2013). Associations among bullying, cyberbullying, and suicide in high school students. Journal of Adolescence, 36, 341-350. http://doi.org/10.1016/j.adolescence.2012.12.001

Brighi, A., Guarini, A., Melotti, G., Galli, S., \& Genta, M. L. (2012). Predictors of victimisation across direct bullying, indirect bullying and cyberbullying. Emotional \& Behavioural Difficulties, 17, 375-388.

http://doi.org/10.1080/13632752.2012.704684

Campbell, M., Spears, B., Slee, P., Butler, D., \& Kift, S. (2012). Victims' perceptions of traditional and cyberbullying and the psychosocial correlates of their victimization. Emotional and Behavioural Difficulties, 17, 389-401.

http://doi.org/10.1080/13632752.2012.70431

Cappadocia, M. C., Weiss, J. A., \& Pepler, D. (2012). Bullying experiences among children and youth with autism spectrum disorders. Journal of Autism and Developmental Disorders, 42, 266-277. http://doi.org/10.1007/s10803$011-1241-x$

Cheng, S. T., Cheung, K. C., \& Cheung, C. K. (2008). Peer victimization and depression among Hong Kong adolescents. Journal of Clinical Psychology, 64, 766-776. http://doi.org/10.1002/jclp.20489

Clarke, K., Cooper, P., \& Creswell, C. (2013). The Parental Overprotection Scale: Associations with child and parental anxiety. Journal of Affective Disorders, 151, 618-624. http://doi.org/10.1016/j.jad.2013.07.007

Dehue, F., Bolman, C., Vollink, T., \& Pouwelse, M. (2012). Cyberbullying and traditional bullying in relation to adolescents' perceptions of parenting. Journal of CyberTherapy \& Rehabilitation, 5(1), 25-34.

Didden, R., Scholte, R. H. J., Korzilius, H., De Moor, J. M. H., Vermeulen, A., O’Reilly, M., ... Lancioni, G. E. (2009). Cyberbullying among students with intellectual and developmental disability in special education settings.

Developmental Neurorehabilitation, 12, 146-151. http://doi.org/10.1080/17518420902971356 
Domingo, M. C. (2012). An overview of the internet of things for people with disabilities. Journal of Network and Computer Applications, 35, 574-596. http://doi.org/10.1016/j.jnca.2011.10.015

Ferdon, C. D., \& Hertz, M. F. (2007). Electronic media, violence, and adolescents: An emerging public health problem. Journal of Adolescent Health, 41, S1-S5. http://doi.org/10.1016/j.jadohealth.2007.08.020

Gillespie, A. A. (2006). Cyber-bullying and harassment of teenagers: The legal response. Journal of Social Welfare \& Family Law, 28, 123-136. http://doi.org/10.1080/09649060600973772

Grigg, D. W. (2010). Cyber-aggression: Definition and concept of cyberbullying. Australian Journal of Guidance and Counselling, 20, 143-156. http://doi.org/10.1375/ajgc.20.2.143

Hassett, M, Lowder, C., \& Rutan, D. (1992). Use of computer network bulletin board systems by disabled persons. In Proceedings of the Annual Symposium on Computer Application in Medical Car (pp. 151-155).

Heiman, T., Olenik-Shemsh, D., \& Eden, S. (2015). Cyberbullying involvement among students with ADHD: Relation to loneliness, self-efficacy and social support. European Journal of Special Needs Education, 30, 15-29. http://doi.org/10.1080/08856257.2014.943562

Heinrichs, R. (2003). Perfect targets: Asperger syndrome and bullying - practical solutions for surviving the social world. Shawnee Mission, Kansas: Autism Asperger Publishing Company.

Hinduja, S., \& Patchin, J. W. (2008). Cyberbullying: An exploratory analysis of factors related to offending and victimization. Deviant Behavior, 29, 129-156.

Hu, H., Chou, W., \& Yen, C. (2016). Anxiety and depression among adolescents with attention-deficit/hyperactivity disorder: The roles of behavioral temperamental traits, comorbid autism spectrum disorder, and bullying involvement. The Kaohsiung Journal of Medical Sciences, 32, 103-109. http://doi.org/10.1016/j.kjms.2016.01.002

Jackson, C. L., \& Cohen, R. (2012). Childhood victimization: Modeling the relation between classroom victimization, cyber victimization, and psychosocial functioning. Psychology of Popular Media Culture, 1, 254-269. http://doi.org/10.1037/a0029482

Kowalski, R. M., \& Fedina, C. (2011). Cyber bullying in ADHD and Asperger Syndrome populations. Research in Autism Spectrum Disorders, 5, 1201-1208.

Kowalski, R. M., \& Limber, S. P. (2007). Electronic bullying among middle school students. Journal of Adolescent Health, 41(6), 22-30. http://doi.org/10.1016/j.jadohealth.2007.08.017

Kowalski, R. M., \& Limber, S. P. (2013). Psychological, physical, and academic correlates of cyberbullying and traditional bullying. Journal of Adolescent Health, 53(1 Suppl), S13-S20.

http://doi.org/10.1016/j.jadohealth.2012.09.018

Kuo, M. H., Orsmond, G., Coster, W., \& Cohn, E. S. (2014). Media use among adolescents with autism spectrum. Autism, 18, 914-923. http://doi.org/10.1177/1362361313497832

Lereya, S. T, Samara, M., \& Wolke, D. (2013). Parenting behavior and the risk of becoming a victim and a bully/victim: A meta-analysis study. Child Abuse and Neglect, 37, 1091-1103.

http://doi.org/10.1016/j.chiabu.2013.03.001

Livingstone, S., Haddon, L., Görzig, A., \& Ólafsson, K. (2011). Risks and safety on the internet: The perspective of European children. LSE, London, UK: EU Kids Online

Livingstone, S., \& Helsper, E. J. (2008). Parental mediation of children's internet use. Journal of Broadcasting \& Electronic Media, 52, 581-599. http://doi.org/10.1080/08838150802437396

Lwin, M. O., Stanaland, \& A., Miyazaki, A. D. 2008. Protecting children's privacy online: How parental mediation strategies affect website safeguard effectiveness. Journal of Retailing, 84, 205-217.

http://doi.org/10.1016/j.jretai.2008.04.004

March, J. S., Parker, J. D., Sullivan, K., Stallings, P., \& Conners, C. K. (1997). The Multidimensional Anxiety Scale for Children (MASC): Factor structure, reliability, and validity. Journal of American Academy of Child and Adolescent Psychiatry, 36, 554-565. 
Mazurek, M. O., Shattuck, P. T., Wagner, M., \& Cooper, B. P. (2012). Prevalence and correlates of screen-based media use among youths with autism spectrum disorders. Journal of Autism \& Developmental Disorders, 42, 17571767. http://doi.org/10.1007/s10803-011-413-8

Mesch, G. S. (2009). Parental mediation, online activities, and cyberbullying. CyberPsychology \& Behavior, 12, 387393. http://doi.org/10.1089/cpb.2009.0068

Millea, M. A., Shea, N. M., \& Diehl, J. J. (2013). Understanding the interaction of temperament and social skills in the development of social anxiety in children with autism spectrum disorders. Autism, 3(4), 1-15.

http://doi.org/10.4172/2165-7890.1000115

Navarro, R., Yubero, S., \& Larranaga, E. (2015). Psychosocial risk factors for involvement in bullying behaviors: Empirical comparison between cyberbullying and social bullying victims and bullies. School Mental Health, 7, 235248. http://doi.org/10.1007/s12310-015-9157-9

Nikken, P., \& de Haan, J. (2015). Guiding young children's internet use at home: Problems that parents experience in their parental mediation and the need for parenting support. Cyberpsychology: Journal of Psychosocial Research on Cyberspace, 9(1), article 3. http://doi.org/10.5817/cp2015-1-3

Nikken, P., \& Schols, M. (2015). How and why parents guide the media use of young children. Journal of Child and Family Studies, 24, 3423-3435. http://doi.org/10.1007/s10826-015-0144-4

Radloff, L. S. (1977). The CES-D Scale: A self-report depression scale for research in the general population. Applied Psychological Measurement, 1, 385-401. http://doi.org/10.1177/014662167700100306

Rideout, V. J., Roberts, D. F., \& Foehr, U. G. (2005). Generation M: Media in the lives of 8-18-year-olds: Executive summary. Menlo Park, CA: Henry J. Kaiser Family Foundation.

Rose, C. A., \& Monda-Amaya, L. E. (2011). Bullying and victimization among students with disabilities: Effective strategies for classroom teachers. Intervention in School and Clinic, 48, 99-107.

Russell, D. W. (1996). UCLA Loneliness Scale (Version 3): Reliability, validity, and factor structure. Journal of Personality Assessment, 66(1), 20-40.

Smahel, D., Wright, M. F., \& Cernikova, M. (2014). Classification of online problematic situations in the context of youths' development. Communications: European Journal of Communication Research, 39, 233-260.

http://doi.org/10.1515/commun-2014-0111

Smith, P. K., Mahdavi, J., Carvalho, M., Fisher, S., Russell, S., \& Tippett, N. (2008). Cyberbullying: Its nature and impact in secondary school pupils. Journal of Child Psychology and Psychiatry, 49, 376-385.

http://doi.org/10.1111/j.1469-7610.2007.01846.x

Soper, D. S. (2013). Interaction! Available at: http://www.danielsoper.com/Interaction/

Sterzing, P. R., Shattuck, P. T., Narendorf, S. C., Wagner, M., \& Cooper, B. P. (2012). Prevalence and correlates of bullying involvement among adolescents with an Autism Spectrum Disorder. Archives of Pediatric and Adolescent Medicine, 166, 1058-1064. http://doi.org/10.1001/archpediatrics.2012.790

Talves, K., \& Kalmus, V. (2015). Gendered mediation of children's internet use: A keyhole for looking into changing socialization practices. Cyberpsychology: Journal of Psychosocial Research on Cyberspace, 9(1), article 4. http://doi.org/10.5817/cp2015-1-4

Van Roekel, E., Scholte, R. H. J., \& Didden, R. (2010). Bullying among adolescents with autism spectrum disorders: Prevalence and perception. Journal of Autism and Developmental Disorders, 40(1), 63-73.

http://doi.org/10.1007/s10803-009-0832-2

Wells, M., \& Mitchell, K. J. (2014). Patterns of internet use and risk of online victimization for youth with and without disabilities. Journal of Special Education, 48, 204-213.

Wolak, J., Mitchell, K., \& Finkelhor, D. (2007). Does online harassment constitute bullying? An exploration of online harassment by known peers and online-only contacts. Journal of Adolescent Health, 41, S51-S58.

http://doi.org/10.1016/j.jadohealth.2007.08.019 
Wright, M. F. (in press). The Buffering Effect of Parental Mediation in the Relationship between Adolescents' Cyberbullying Victimization and Adjustment Difficulties. Child Abuse Review.

Wright, M. F. (2015). Cyber victimization and adjustment difficulties: The mediation of Chinese and American adolescents' digital technology usage. Cyberpsychology: Journal of Psychosocial Research in Cyberspace, 9(1), article 7. http://doi.org/10.5817/CP2015-1-7

Wright, M. F. (2016). Cyber victimization and substance use among adolescents: The moderation of perceived social support. Journal of Social Work Practice in the Addictions. http://doi.org/10.1080/1533256X.2016.1143371

Wright, M. F., \& Li, Y. (2012). Kicking the digital dog: A longitudinal investigation of young adults' victimization and cyber-displaced aggression. Cyberpsychology, Behavior, \& Social Networking, 15, 448-454.

http://doi.org/10.1089/cyber.2012.0061

Wright, M. F., Li Y. (2013). The association between cyber victimization and subsequent cyber aggression: The moderating effect of peer rejection. Journal of Youth \& Adolescence, 42, 662-674. http://doi.org/10.1007/s10964012-9903-3

Wright, M.F., Li, Y., \& Shi, J. (2014). Chinese adolescents' social status goals: Associations with behaviors and attributions for relational aggression. Youth \& Society, 46, 566-588. http://doi.org/10.1177/0044118X12448800

Ybarra, M. L., Diener-West, M., \& Leaf, P. J. (2007). Examining the overlap in internet harassment and school bullying: Implications for school intervention. Journal of Adolescent Health, 41(6 Suppl 1), S42-S50.

http://doi.org/10.1016/j.jadohealth.2007.09.004

Ybarra, M. L., \& Mitchell, K. J. (2004). Online aggressor/targets, aggressors, and targets: A comparison of associated youth characteristics. Journal of Child Psychology and Psychiatry, 45, 1308-1316.

http://doi.org/10.1111/jcpp.2004.45.issue-7

Ybarra, M. L., Mitchell, K. J., Palmer, N. A., \& Reisner, S. L. (2015). Online social support as a buffer against online and offline peer and sexual victimization among U.S. LGBT and non-LGBT youth. Child Abuse and Neglect, 39, 123136. http://doi.org/10.1016/j.chiabu.2014.08.006

\section{Correspondence to:}

Michelle F. Wright

Pennsylvania State University

Department of Psychology

Child Study Center

264 Moore Building

University Park, PA 16802

Email: mfw5215@psu.edu

\section{About Author}

Michelle F. Wright is a research associate at Pennsylvania State University and a postdoctoral research fellow at Masaryk University. Her research focus is on the contextual factors which influence children's, adolescents', and young adults' involvement in aggressive behaviors, with a special interest in social goals, peer status, and cultural values. She has published on these topics, with her most recent work focused on culture and anonymity, and their role in cyberbullying among adolescents.

Editorial record: First submission received on September 30, 2016. Revision received on January 24, 2017. Accepted for publication on May 5, 2017. The article is part of Special Issue "Internet use and disability - Risks, opportunities and challenges" guest edited by Emma Sorbring and Martin Molin. 